\title{
A Note on the Text
}

THE EARLIEST SELECTIONS in Thoreau's Wildflowers are from I850, the first year in which Thoreau made regular dated observations of the flora of Concord, though he had little botanical experience at that point. This was also around the time he began to see the Journal as a work of art in its own right, not simply a quarry from which to mine other books and essays.

The text is drawn from the fourteen-volume 1906 edition of The Journal of Henry D. Thoreau, edited by Bradford Torrey and Francis H. Allen. Each selection for the period between May 31, I850, and September 3, I854, has been checked against the Princeton University Press edition of the Journal, of which eight volumes have so far been published. Later selections have been checked against the unedited transcript of the Journal, made available online by the University of California Santa Barbara Library.

Bracketed text (mostly names of plants) has been added by Torrey and Allen or by me. Omitted text is indicated by ellipses without brackets. Penciled additions by Thoreau, rendered as footnotes in the 1906 edition, are included in parentheses. Words and phrases in italics were emphasized in the original.

The Princeton edition and unedited transcripts offer the most accurate available version of what Thoreau actually wrote, including his misspellings, sentence fragments, idiosyncratic capitalization, and haphazard punctuation. I have referred to these texts to correct misreadings, restore paragraph breaks, and change the spellings and punctuation used in the I906 edition to something closer to Thoreau's original version.

In I854, when Walden was published, and in 1906, when Thoreau's Journal appeared in full (or nearly so), authors and editors had definite ideas 


\section{Note on the Text}

of what was required to make a manuscript fit for the public. Those ideas included an approach to punctuation that today seems overly fussy. In The New Thoreau Handbook, Michael Meyer mentions a single sentence in Walden that contains three hundred fifty words, forty commas, ten semicolons, and one dash. Many passages in the 1906 edition of the Journal are similarly equipped with commas, semicolons, or even a comma plus a dash. The result is a leisurely, meditative, even sleepy pace.

Thoreau's natural style, as seen in the Princeton edition and transcripts of the Journal, was very different. Like Emily Dickinson in her verse, Thoreau's favorite punctuation mark was the dash, and he used it in lieu of a comma, semicolon, or paragraph break. As in Dickinson, the dash lends his words a tense, taut, flashing quality that in the nineteenth century was called "nervous." Thoreau often uses a dash to set off a sudden insight from the observation that prompted it. He is sparing with commas in the Journal, and rarely uses a semicolon. He is not at all averse to a sentence fragment. The style of his Journal is in fact startlingly modern.

Thoreau's spelling, though erratic, is also more modern and more American than Torrey and Allen made it appear. Where Thoreau wrote "today" and "tonight," Torrey and Allen made it "to-day" and "to-night." Where Thoreau wrote "cornfield" and "cardinal flower," Torrey and Allen made it "corn-field" and "cardinal-flower." They Britishized some spellings, changing "center" to "centre" and "gray" to "grey." They consolidated many short paragraphs and added many exclamation points, giving the text an effusive tone that is sometimes unwarranted. I have reversed these changes and chosen standard spellings where variants appear in the original (for example, "catnip" rather than "catnep").

In some cases I have preferred a reading in the 1906 edition to one in the Princeton edition. For instance, for June 22, I851, the 1906 editors have, "The tall buttercup stars the meadow on another side, telling of the wealth of dairies." The Princeton editors replace "dairies" with "daisies." This might seem a more sensible reading, except that a year later, in a passage about cowslips, Thoreau speculates that the yellow blossom of the cowslip colors the butter of the dairy cows that eat it. If cowslips suggested dairies to Thoreau, it seems likely that buttercups (and perhaps butter-and-eggs) suggested them as well. Similarly, the 1906 edition for September 28, I85I, has this: "Though the moss is comparatively dry, I 


\section{Note on the Text}

cannot walk without upsetting the numerous pitchers, which are now full of water, and so wetting my feet." The Princeton edition makes this "the moist is comparatively dry," a reading I find unlikely - not only because it makes for peculiar English but because in the previous sentence Thoreau mentions walking over coarse reddish moss. 
This page intentionally left blank 